\title{
Psychological Effects of War and Violence on Children
}

\section{Fuaad Mohammed Freh*}

Department of Psychology, University of Anbar, College of Education, Iraq

\section{Introduction}

Between 1945 and 1992, there were more than 149 major wars, killing more than 23 million people. Children have, of course, always been caught up in warfare. They usually have little choice but to experience, at minimum, the same horrors as their parents- as casualties or even combatants. Recent developments in warfare have significantly heightened the dangers for children. It is, during the last decade, that 2 million children have been killed; 4-5 million have been disabled, more than 1 million orphaned or separated from their parents, and 12 million dislocated from their home [1].

War and terrorism, are man perpetrated acts of violence, have emotionally and psychologically affected generations of children and young people for the rest of their lives. A study has estimated that one out of three children who live in war zones could be vulnerable to develop some form of PTSD, psychopathological symptoms, and lower psychosocial functioning levels during their life time, which points to the volatile and violent environment they are living in [2]. Among those children exposed to war-related stressors for a longer period, it is generally estimated that the prevalence of posttraumatic stress symptomatology varies from 10 to $90 \%$, manifested by anxiety disorders such as posttraumatic stress disorder and other psychiatric morbidities including depression, disruptive behaviors, and somatic symptoms [3].

\section{Reactions of Children}

Exposure to war trauma and terror has clearly been found to cause high levels of stress among children which has been associated with the development of a wide range of psychological problems [4]. However, it is impossible for children to go through upheavals of this kind without showing their effect in difficult behavior and in variations from normality. Infantile nature has certain means at its disposal to deal with shocks, deprivations and upsets in life. Studies found that, in some children, abnormal withdrawal from the world has been noted. Some become emotionless like an automaton. Some emotional outbreaks of hysterical type have also been reported. However, in general, sooner or later the child returns to good relations with the outer world. The recovery time depends on some factors like extent of damage, treatment in post-traumatic period, the coping capabilities of the child which is further dependent on the age of the child. Also in some cases, a child exposed to a lot of death and destruction at an early age can have a heart that can be scarred no further. They become indifferent to the sufferings of others.

\section{How is Children Coping with Post-War Trauma?}

\section{Healthy coping with little or no reaction}

Despite exposure to a spectrum of horrific atrocities not all exposed children exhibit long-term health problem and some children are able to adapt with only minimal symptomatology. One suggestion is that variation in resilience- the likelihood of problems developing is related to psycho-social coping factors. Folkman et al. proposed that people employ various defenses and coping strategies against stressors to protect their psychological and emotional well-being [5]. Broadly, some of the protective factors that have been identified are the following: the child's capacity to recognize and avoid dangers, the child's ability to use adults for caretaking activities, the child's capacity to manage anxiety, the child's ability to devote him/her to a cause and to find meaning in the experience. Other factors include the degree of social, community, and family cohesiveness and perceived social, as well as shared values and beliefs systems with children and those around them. Temperamental and biological factors modulating stress response have been mentioned but little is known of their specific protective value.

\section{Acute emotional and behavioural effects}

Studies referred that although children demonstrated few psychological reactions in response to their experience of being in a bombing, this was altered with increased proximity of the zone of impact, and the intensity and lethality of exposure [6]. Eighty-seven percent of those children exposed to chemical attack weapons showed psychological symptoms and high traumatic event level several months after the attack [7]. The majority of children exposed to the ongoing stressors of war will experience significant psychological morbidity.

Dyregrov, et al. interviewed a group of 94 Iraqi children who were exposed to the bombing of the Al-Ameriyah shelter on February 13th, 1991 [8]. This was one of the most extreme attacks targeting Iraqi civilians. Around $80 \%$ of the 94 children were found to have developed PTSD symptoms. The majority of them also experienced indications of depression and remained anxious and afraid of losing other members of their family. Also, Razoki et al. noted that $14 \%$ of Iraqi school children exposed to major war-related stressors met the criteria for current probable PTSD with full and partial PTSD [9]. Thabet and Vostanis surveyed Palestinian children 6-11 years and found that $73 \%$ reported PTSD symptoms of at least mild intensity and $41 \%$ reported severe PTSD reactions [10].

\section{Long Term Effects}

There is a paucity of studies looking at the long-term psychological consequences and mental health following traumatic situations. Thabet and Vostanis found that the $40 \%$ of children in the Gaza strip who had been initially met criteria for current probable PTSD decreased about $10 \%$ in PTSD symptoms one year later with the onset of the peace process [11]. Although a child's initial exposure to war related trauma may have been relatively circumscribed in time and space, there are a spectrum of secondary stressors in the aftermath of war, which continue to impact on the child and his family (i.e., economic-social disruption, loss and separation from loved ones, malnutrition, and illness [12].

A study surveyed a sample of school-age children four years after the war found that most of the children continued to live in impoverished communities, in which the compromised social infrastructure

*Corresponding author: Fuaad Mohammed Freh, Department of Psychology, University of Anbar, College of Education, Iraq, Tel.: 009647830485026; E-mail: fuaadfreh@yahoo.com

Received October 03, 2015; Accepted October 06, 2015; Published November 17,2015

Citation: Freh FM (2015) Psychological Effects of War and Violence on Children. J Psychol Abnorm S1: e001. doi:10.4172/jpab.S1-e001

Copyright: () 2015 Freh FM. This is an open-access article distributed under the terms of the Creative Commons Attribution License, which permits unrestricted use, distribution, and reproduction in any medium, provided the original author and source are credited. 
represented an ongoing stressor manifested by dangerous and unhealthy conditions such as overcrowded conditions, unsafe playgrounds without access to sports fields. The vast majority of children felt unsafe in the streets, experienced school problems, and was frequently ill. Nevertheless, the children were seen as adopting somehow healthy strategies to cope with stressful events in their lives [13].

In the same vein, $43 \%$ of Lebanese children were found to continue to manifest posttraumatic stress symptoms even 10 years after their experience of being in war-related traumatic events [14]. The biological impact of war-related traumas is directly related to the severity of the experience, duration, and the impact of the stressors on bodily integrity, the stress response system and/or its interference with life sustaining support systems. It is known that exposure to intense acute and chronic stressors during the developmental years has enduring neurobiological effects vis-a-vis the stress response and neurotransmitter systems with subsequent increased risk of anxiety and mood disorders, aggressive dyscontrol problems, hypoimmune dysfunction, medical morbidity, structural changes in the CNS, and early death [15].

Despite the evidence in research that exposure to war and violence can lead to high levels of stress and the development of PTSD symptoms, psychological studies have not sufficiently studied the effects of the experience on mental health among children in the Middle East countries, e.g., Iraq. The widespread experience of potentially traumatic events in Iraq has had a major impact on, health and well-being, included long-term physical and psychological harm to its children and adults alike. According to the WHO, more than half a million children in Iraq might be in need of clinical assistance, including psychotherapy. Moreover, there are approximately 5.7 million Iraqi children studying at primary and secondary schools; it has been speculated that at least $10 \%$ of them are in dire need of psychotherapy as a result of experiencing highly dangerous (potential trauma inducing) events [16].

A fundamental question is whether such events inevitably lead to deterioration in mental health or whether some forms of resilience and coping emerge. For example, a hopeful conceptualization is that children may develop resilience and adapt in one way or another to stressful events because of the continual exposure to such events, through a form of "psychological immunization" [17]. However, such a simple view is questionable.

\section{Conclusion}

The growing threat of terrorism worldwide in the late 1990s and the early years of the second millennium have heightened the health professional's awareness of disasters as a potentially important determinant of population health and suggest a pressing need both to identify key areas of consensus in post-disaster research and to highlight areas that require additional studies [18]. As a result, a substantial body of literature after wars e.g. war in Iraq and Afghanistan [19] and terrorist attacks, e.g., September 11, 2001 in New York City [20] were conducted. These studies had a profound influence on the empirical work of PTSD. However, much of this work sought to understand the psychological sequelae of exposure to dangerous events among persons who had fought in or been the victims of war and violent conflict.

The study suggested that the psychological effects of war and violence on children depend on a range of factors such as the pre-war scenario, atrocities to which the child is subjected during the war, and post-war conditions. The collection of data from war-like situations for further research is difficult. Thus there are a number of research questions that deserve further elucidation in delineating the effects of trauma and its mediators on the psychological well-being of children, such as the variation of psychological response to trauma with age and cognitive development; the relationship between specific trauma exposure and psychological consequences; whether there is a commonality of psychological responses to trauma exposure regardless of the specific trauma manifested by a spectrum of internalizing and externalizing behaviors; role of predisaster, peridisaster, and postdisaster variable and their relative valence in predicting acute and chronic posttraumatic stress symptomatology and other psychiatric morbidities to name to few.

\section{References}

1. Sivard RL (1993) World Military and Social Expenditures. World Priorities Inc. Washington.

2. Freh FM, Chung MC, Dallos R (2013) In the shadow of terror: Posttraumatic stress and psychiatric co-morbidity following bombing in Iraq: The role of shattered world assumptions and altered self-capacities. Journal of Psychiatric Research 47: 215-225.

3. Allwood MA, Bell-Dolan D, Husain SA (2002) Children's trauma and adjustment reactions to violent and nonviolent war experiences. J Am Acad Child Adolesc Psychiatry 41: 450-457.

4. Shahar G, Cohen G, Grogan KE, Barile JP, Henrich CC (2009) TerrorismRelated Perceived Stress, Adolescent Depression, and Social Support From Friends. Pediatrics, 124: 235-240.

5. Folkman S, Lazarus RS, Gruen RJ, DeLongis A (1986) Appraisal, coping health status, and psychological symptoms. J Pers Soc Psychol 50: 571-579.

6. North CS, Pfefferbaum B, Kawasaki A, Lee S, Spitznagel EL (2011) Psychosocial adjustment of directly exposed survivors 7 years after the Oklahoma City bombing. Compr Psychiatry 52: 1-8.

7. Ahmad A, Sofi MA, Sundelin-Wahlsten V, von Knorring AL (2000) Posttraumatic stress disorder in children after the military operation "Anfal" in Iraqi Kurdistan. Eur Child Adolesc Psychiatry 9: 235-243.

8. Dyregrov A, Gjestad R, Raundalen M (2002) Children exposed to warfare: a longitudinal study. J Trauma Stress 15: 59-68.

9. Razokhi AH, Taha IK, Taib NI, Sadik S, Al Gasseer N (2006) Mental health of Iraqi children. Lancet 368: 838-839.

10. Thabet AA, Vostanis $P$ (1999) Post-traumatic stress reactions in children of war J Child Psychol Psychiatry 40: 385-391.

11. Thabet AA, Abed $Y$, Vostanis $P$ (2004) Comorbidity of PTSD and depression among refugee children during war conflict. J Child Psychol Psychiatry 45: 533542 .

12. Khamis V (2012) Impact of war, religiosity and ideology on PTSD and psychiatric disorders in adolescents from Gaza Strip and South Lebanon. Soc Sci Med 74: 2005-2011.

13. Baràth $A$ (2002) Psychological status of Sarajevo children after war: 1999-2000 survey. Croat Med J 43: 213-220.

14. Macksoud MS, Aber JL (1996) The war experiences and psychosocial development of children in Lebanon. Child Dev 67: 70-88.

15. Heim C, Meinschmidt G, Nemeroff, CB (2003) Neurobiology of early-life stress. Psychiatric Annals, 33: 18-26.

16. Alhasnawi S, Sadik S, Rasheed M, Baban A, Al-Alak MM, et al. (2009) The prevalence and correlates of DSM-IV disorders in the Iraq Mental Health Survey (IMHS). World Psychiatry 8: 97-109.

17. Okasha, T, Elkholy H (2012) A synopsis of recent influential papers published in psychiatric journals (2010-2011) from the Arab World. Asian Journal of Psychiatry 5: 175-178.

18. Galea S, Nandi A, Vlahov D (2005) The epidemiology of post-traumatic stress disorder after disasters. Epidemiol Rev 27: 78-91.

19. Thomas JL, Wilk JE, Riviere LA, McGurk D, Castro CA, et al. (2010) Prevalence of mental health problems and functional impairment among Active Component and National Guard soldiers 3 and 12 months following combat in Iraq. Archives of General Psychiatry 67: 614-623.

20. Cardenas J, Williams K, Wilson JP, Fanouraki G, Singh A (2003) PTSD, major depressive symptoms, and substance abuse following September 11, 2001, in a Midwestern university population. International Journal of Emergency Mental Health 5: 15-28. 